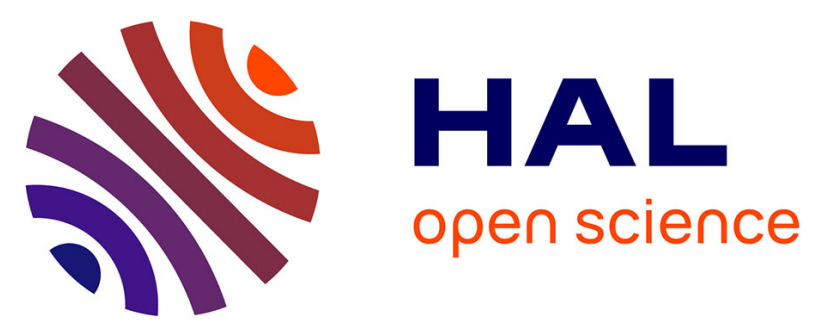

\title{
Analysis of melanoma-related microRNAs expression during the spontaneous regression of cutaneous melanomas in MeLiM pigs
}

Michael Baco, Chia-Ying Chu, Stephan Bouet, Claire Gaillard, Emmanuelle Bourneuf, Fabienne Le Provost, Chia-Yu Chu, Silvia Vincent-Naulleau

\section{To cite this version:}

Michael Baco, Chia-Ying Chu, Stephan Bouet, Claire Gaillard, Emmanuelle Bourneuf, et al.. Analysis of melanoma-related microRNAs expression during the spontaneous regression of cutaneous melanomas in MeLiM pigs. Pigment Cell and Melanoma Research, 2014, 27 (4), pp.668-670. 10.1111/pcmr.12243 . hal-01193803

\section{HAL Id: hal-01193803 https://hal.science/hal-01193803}

Submitted on 27 May 2020

HAL is a multi-disciplinary open access archive for the deposit and dissemination of scientific research documents, whether they are published or not. The documents may come from teaching and research institutions in France or abroad, or from public or private research centers.
L'archive ouverte pluridisciplinaire HAL, est destinée au dépôt et à la diffusion de documents scientifiques de niveau recherche, publiés ou non, émanant des établissements d'enseignement et de recherche français ou étrangers, des laboratoires publics ou privés. 


\section{(a) Title of paper:}

Analysis of melanoma-related microRNAs expression during the spontaneous regression of cutaneous melanomas in MeLiM pigs.

\section{(b) Full Name of authors}

BACO Michael 1,2,3, CHU Chia-ying 4,5, BOUET Stephan 1,2,3, ROGEL-GAILLARD Claire 2,3, BOURNEUF Emmanuelle 1,2,3 , LE PROVOST Fabienne 2,3 , CHU Chia-Yu 5,6 , VINCENT-NAULLEAU Silvia 1,2,3.

\section{(c) Institutional Affiliation:}

1. CEA, DSV, IRCM, SREIT, Laboratoire de Radiobiologie et d'Etude du génome, Jouy en Josas, France.

2. INRA, UMR1313 Génétique Animale et Biologie Intégrative, Jouy en Josas, France.

3. AgroParisTech, UMR1313 Génétique Animale et Biologie Intégrative, Jouy en Josas, France. Mail : INRA GABI, Domaine de Vilvert, 78352, JOUY-EN-JOSAS cedex, FRANCE 4. Institute of Zoology, College of Life Science, National Taiwan University, Taipei, Taiwan. Mail: Institute of Zoology, National Taiwan University, No. 1 Sec. 4 Roosevelt Road, Taipei, Taiwan, 10617

5. Center for Systems Biology, National Taiwan University, Taipei, Taiwan. Mail: 1, Roosevelt Rd., Section 4, Taipei 10617, Taiwan

6. Department of Dermatology, National Taiwan University Hospital and National Taiwan University College of Medicine, Taipei, Taiwan.

Mail: Department of Dermatology, National Taiwan University Hospital, 15F No.7.Chung San South Road, Taipei 10002, Taiwan.

\section{(d) Corresponding authors:}

Silvia VINCENT-NAULLEAU, DVM, PhD

Address: CEA, DSV, IRCM, SREIT, Laboratoire de Radiobiologie et d'Etude du génome, Domaine de Vilvert, 78352, JOUY-EN-JOSAS cedex, FRANCE

E-mail : silvia.vincentn@cea.fr

Tel: +33 (0)134652810

Fax: +33 (0)134652964 
Dear Editor,

Treatment of advanced cutaneous melanoma is still challenging and new data on melanoma biology are required. MicroRNAs (miRNAs) represent an emerging field in melanoma understanding. These small regulators of gene expression, involved in melanoma development and progression (Da cruz et al., 2012), showed promising results as biomarkers (Nair et al., 2012). As each miRNA could regulate multiple protein-coding genes and conversely, one gene could be targeted by different miRNAs (Bartel et al., 2009), the dysregulation of miRNAs could significantly impact various pathways and cells behavior. In this report, we studied the Melanoma-bearing Libechov Minipigs, a model of complete spontaneous regression of invasive cutaneous melanoma (Vincent-Naulleau et al., 2004), in order to investigate if miRNAs could be involved in this process.

We evaluated the differential expression of 9 melanoma-related miRNAs (reviewed in Da cruz et al., 2012; Igoucheva and Alexeev, 2009 and Jiang et al., 2012) by quantitative PCR (qPCR) in MeLiM melanomas. We compared8 tumors showing evidence of regression (clinical drying or graying aspect and tumor size reduction) to 8 progressing tumors(clinical and histological characterization as indicated in Vincent-Naulleau et al., 2004) (Figure 1). ThreemiRNAs showed no significant differential expression between the two conditions (let-7a, miR-34a and miR-182). Among the significant differentially expressed miRNAs, only miR-92a showed a down-regulation in regressing melanoma (Fold Change $(F C)=0.60, p=0.0148$ ), whereas five miRNAs (miR-21, miR-221, miR-222, miR-193b and let-7b) were found up-regulated with a FC ranging from 2.00 to 3.97 ( $p<0.05)$ (Figure 1). Interestingly, in regressive swine tumors, miR-92a, let-7b and miR-193b had an expression profile opposite to the profile observed during the progression of human cutaneous melanoma (Igoucheva and Alexeev, 2009; Schultz et al., 2008; Chen et al., 2010). This observation could suggest that these three miRNAs could be potential actors in the regression process of cutaneous melanoma in the MeLiM model. Among those, the tumor-suppressor miR-193b showed the highest up-regulation ( $F C=3.97, p<0.01$ ).

Thus, as miR-193b was up-regulated in regression, our hypothesis was that its known targets should be concomitantly down-regulated. According to Chen et al. (2010), miR-193b directly and indirectly down-regulated 314 mRNAs in a human melanoma cell line. In a previous study, we analyzed the expression of 11,216 mRNAs during swine melanoma regression (Rambow et al., 2008). Out ofthe 314 genes of interest, 211 had a specific probe on the Porcine Genome Arrayused in our previous study (GeneChip ${ }^{\circledR}$, Affymetrix). We extracted the Log2(FC) values of these 211 genes, to build a "miR-193b-regulated" genes set and a "miR-193b-non-regulated" genes set (i.e. all other genes on the micro-array, $n=11,005)$. A permutation test revealed that miR-193b-regulated set is enriched in down-regulated genes $(p=1.61 \mathrm{e}-37)$, as indicated by a distinctLog2(FC) cumulative 
distribution function (CDF) of the miR-193b-regulated genes set, compared to the Log2(FC)-CDF of the miR-193b-non-regulated genes set (Kolmogorov-Smirnoff $p=2.49 \mathrm{e}-19$, figure 2 ). In order to identify the potential function of the concomitant up-regulation of miR-193b and the regulation of its down-stream genes, the 211 genes set and their respective fold change have been imported in Ingenuity Pathway Analysis (IPA, Ingenuity ${ }^{\circledR}$ Systems,www.ingenuity.com)for a core analysis and upstream regulators prediction. The core analysis highlighted a role for 77 of these genes in the "cell cycle"pathway and the most enriched pathway identified is "DNA replication, recombination and repair" (Table 1A), in accordance with our previous results. In addition, the upstream regulator analysis identified 5 transcriptional regulators potentially inhibited during cutaneous melanoma regression: E2F1, MYC, TBX2, E2F2 and TP63 (Table 1B). Most of these genes are described as putative oncogenes or biomarkers of poor prognosis in melanoma. Among them, E2F1 (in the miR193b-regulated gene set, $\log 2(\mathrm{FC})=-0.732)$ is a predicted target of miR-193b (TargetScan6.2, $h t t p: / / w w w . t a r g e t s c a n . o r g /$ ). Thus, we may postulate that during the early step of cutaneous melanoma regression, the up-regulation of miR-193b leads to an indirect down-regulation of numerous cell-cycle related genes via the modulation of E2F1. Future studies are required to explore this issue.

In conclusion, we show that in our model, melanoma-related miRNAs (let-7b, miR-92a and miR-193b) are expressed in an opposite direction during regression of cutaneous melanoma compared to its progression in human. In addition, we showed a concomitant up-regulation of miR193b and down-regulation of its downstream genes. IPA analysis revealed that miR-193b could regulate cell-cycle related genes during regression of cutaneous melanoma. The present work highlight the potential implication of miRNAs in the early step of cutaneous melanoma regression in swine and require future research to conclude about their potential value as therapeutic and diagnosis tools.

\section{Acknowledgements}

This work was supported by CEA, INRA, Université Evry Val d'Essonne, France-Taiwan Orchid Program-Joint Project (NSC 100-2911-I-002-501-MY2) and National Science Council of Taiwan (NSC 99-2314-B-002-005-MY3). We thank Jean-Jacques Leplat for tumor excisions, Fabrice Andreoletti and Philippe Bacon for daily care of animals and the Iso Cell Express platform (INRA, GABI - UMR1313) for assistance in RT-qPCR. MeLiM founder animals were imported from the Institute of Animal Physiology and Genetics, Academy of Sciences of the Czech Republic, 27721 Libechov, Czech Republic. 


\section{References}

Bartel, D. P. (2009). MicroRNAs: target recognition and regulatory functions. Cell 136, 215-33.

Chen, J., Feilotter, H. E., Pare, G. C., Zhang, X., Pemberton, J. G., Garady, C., Lai, D., Yang, X., and Tron, V. A. (2010). MicroRNA-193b represses cell proliferation and regulates cyclin D1 in melanoma. The American journal of pathology 176, 2520-9.

Da Cruz, A. T., and Jasiulionis, M. G. (2012). miRNAs and Melanoma: How Are They Connected? Dermatology research and practice 2012, 528345.

Igoucheva, O., and Alexeev, V. (2009). MicroRNA-dependent regulation of cKit in cutaneous melanoma. Biochemical and biophysical research communications 379, 790-4.

Jiang, L., Lv, X., Li, J., Li, J., Li, X., Li, W., and Li, Y. (2012). The status of microRNA-21 expression and its clinical significance in human cutaneous malignant melanoma. Acta histochemica 114, 582-8.

Nair, V. S., Maeda, L. S., and Ioannidis, J. P. (2012). Clinical outcome prediction by microRNAs in human cancer: a systematic review. Journal of the National Cancer Institute 104, 528-40.

Rambow, F., Piton, G., Bouet, S., Leplat, J. J., Baulande, S., Marrau, A., Stam, M., Horak, V., and Vincent-Naulleau, S. (2008). Gene expression signature for spontaneous cancer regression in melanoma pigs. Neoplasia 10, 714-26, 1 p following 726.

Schultz, J., Lorenz, P., Gross, G., Ibrahim, S., and Kunz, M. (2008). MicroRNA let-7b targets important cell cycle molecules in malignant melanoma cells and interferes with anchorage-independent growth. Cell research 18, 549-57.

Vincent-Naulleau, S., Le Chalony, C., Leplat, J. J., Bouet, S., Bailly, C., Spatz, A., Vielh, P., Avril, M. F., Tricaud, Y., Gruand, J., et al. (2004). Clinical and histopathological characterization of cutaneous melanomas in the melanoblastoma-bearing Libechov minipig model. Pigment cell research / sponsored by the European Society for Pigment Cell Research and the International Pigment Cell Society 17, 24-35.

Figure 1: MiRNAs expression changes during regression of swine cutaneous melanoma. Boxplots represent the relative expression of melanoma-related miRNAs in regressing melanoma $(D+49$, $n=8$ tumors, grey boxes) compared to progressing ones ( $D+8, n=8$ tumors, white boxes), determined by quantitative PCR. We excised one progressive and one regressive tumor on the same animal but all the others, were excised on 14 different MeLiM piglets to limit impact of the animal genetic background. Relative quantification was calculated by $2^{\text {-ddct }}$ methods, using miR-191 as a reference gene. The Normfinder analysis revealed that miR-191 (stability value 0.140) was the best normalizer in our model among U6 (stability value 0.311 ) and miR-423 (0.173), in accordance with previous reports (Peltier et al., 2009; Saldanha et al., 2013). Stem-loop reverse transcription has been performed in triplicate for each miRNA and each CDNA product has been quantified by qPCR in triplicate. Differences between groups were assessed by a Mann-Whitney U-test (Ns- no significant difference, ${ }^{*}-p<0.05, * *$ - $\left.p<0.01\right)$.

Figure 2: Comparison of Log2FC distribution of miR-193b-regulated and non-regulated genes in regressing melanoma. Log2FC cumulative frequency distribution of miR-193b targeted genes and non-miR-193b targeted genes during the early phase of regression compared to progression. Filled 
145 line: Log2FC cumulative frequency distribution of genes that are not regulated by miR-193b. Dotted 146 line: Log2FC cumulative frequency distribution of genes regulated by miR-193b.

149 Table 1: IPA analysis results of the miR-193b-regulated genes. (A) Molecular and cellular functions 150 associated with the 211 genes regulated by miR-193b. The top-5 functions identified are ranked 151 according to their $p$-value. (B) IPA upstream regulators prediction results. This analysis enables to 152 identify the cascade of upstream transcriptional regulators that could explain the observed gene 153 expression changes in the dataset and illuminate the biological activities occurring in the regressing 154 tumors. The top-5 upstream transcriptional regulatorsare presented with their predicted activation 155 or inhibition state according to the expression of their downstream genes in regression. 
Figure 1

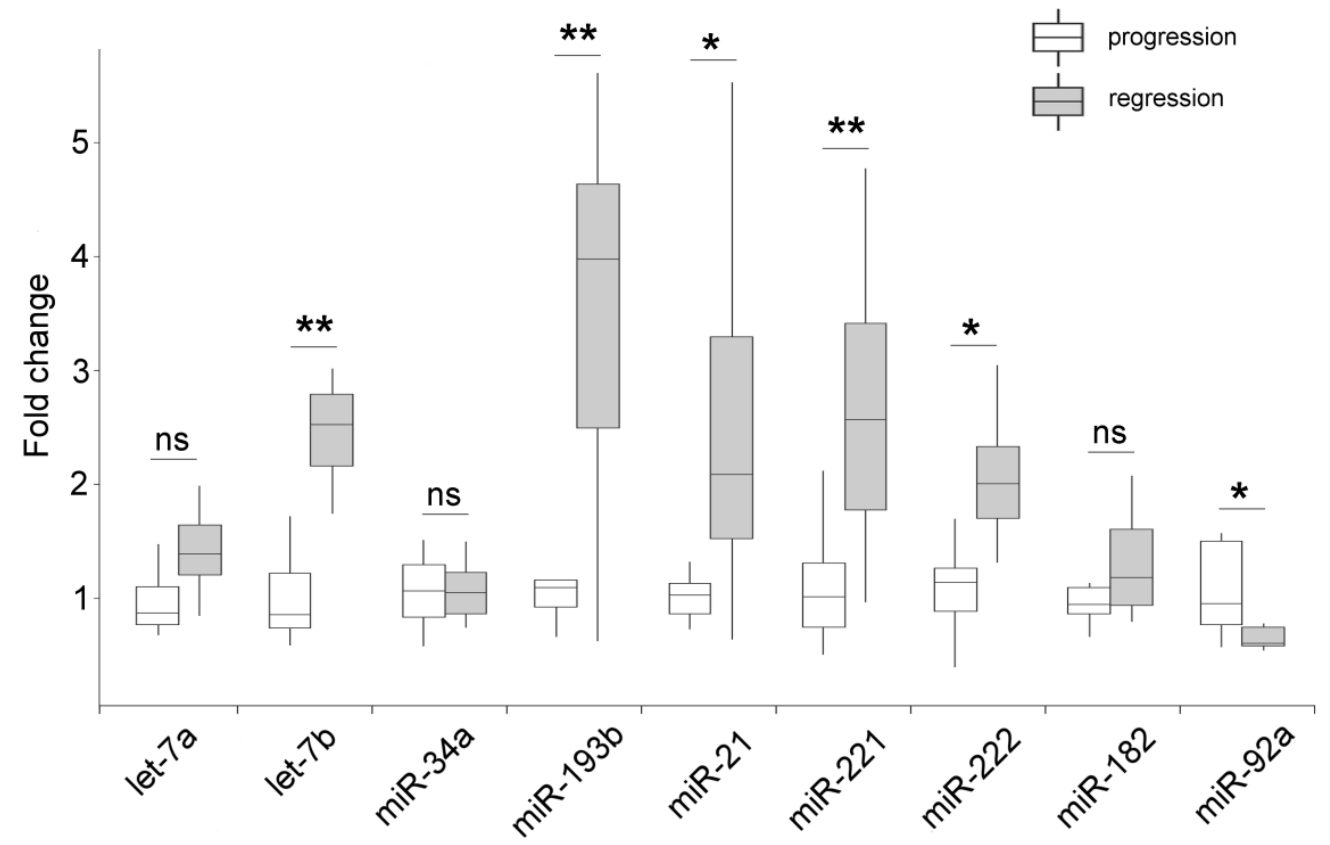

159 Figure 2

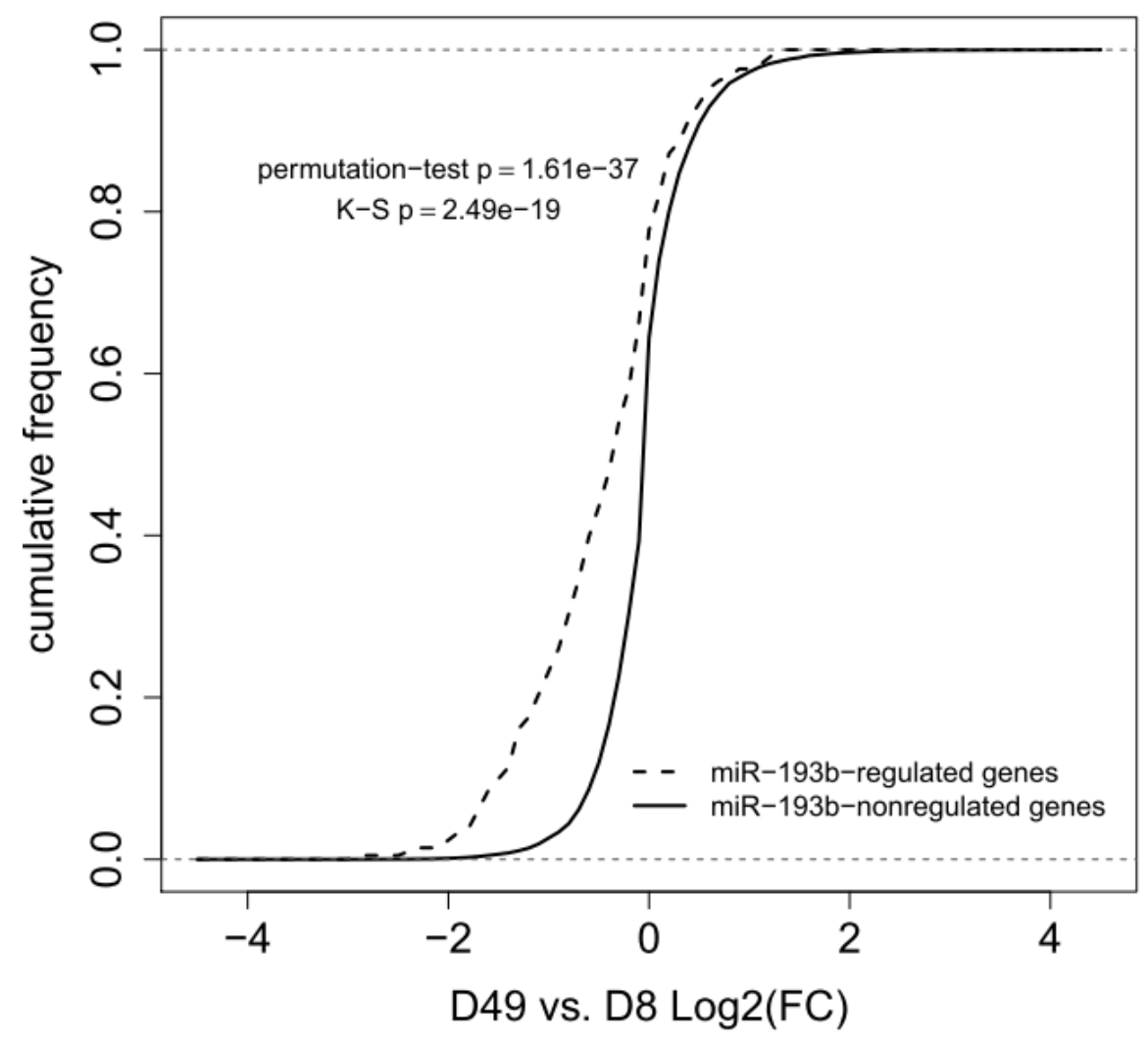


164 A

\begin{tabular}{cll}
\hline Name & p-value & \# Molecules \\
\hline Cell Cycle & $8.19 \mathrm{E}-17$ & 77 \\
\hline Cellular Assembly and Organization & $2.11 \mathrm{E}-11$ & 64 \\
\hline DNA Replication, Recombination, and Repair & $2.11 \mathrm{E}-11$ & 80 \\
\hline Cellular Function and Maintenance & $1.57 \mathrm{E}-09$ & 37 \\
\hline Cellular Growth and Proliferation & $1.89 \mathrm{E}-09$ & 85 \\
\hline
\end{tabular}

165

166

B

\begin{tabular}{|c|c|c|c|c|c|}
\hline $\begin{array}{l}\text { Upstream } \\
\text { Regulator }\end{array}$ & $\begin{array}{l}\text { Log } \\
\text { Ratio }\end{array}$ & $\begin{array}{l}\text { Predicted } \\
\text { Activation } \\
\text { State }\end{array}$ & $\begin{array}{c}\text { Activation } \\
\text { z-score }\end{array}$ & $\begin{array}{c}\text { p-value of } \\
\text { overlap }\end{array}$ & Target molecules in dataset \\
\hline E2F1 & $-0,732$ & Inhibited & -4.477 & $5,08 \mathrm{E}-20$ & $\begin{array}{l}\text { BRCA1, CCNA2, CDC25A, CDC6, CDCA4, CDK1, } \\
\text { CHEK1, DNMT1, E2F1, ECT2, EZH2, FBXO5, FEN1, } \\
\text { GMNN, HELLS, HMGB1, KIAA0101, MCL1, MCM4, } \\
\text { MCM5, MCM6, MCM7, NDC80, PCNA, POLD1, } \\
\text { RACGAP1, RRM2, STMN1, TK1, TOP2A, TYMS }\end{array}$ \\
\hline TBX2 & & Inhibited & -4.231 & $6,68 \mathrm{E}-20$ & $\begin{array}{c}\text { ASF1B, CCNA2, CDC6, CDCA5, CDK1, CDT1, } \\
\text { CHAF1B, CHEK1, DNMT1, E2F1, ELK3, EZH2, } \\
\text { HELLS, MCM4, MCM5, MCM6, MCM7, PKMYT1 }\end{array}$ \\
\hline E2F2 & & Inhibited & -2.236 & $5,57 \mathrm{E}-14$ & $\begin{array}{c}\text { CCNA2, CDC25A, CDC6, CDCA4, CDK1, E2F1, EZH2 } \\
\text { MCM4, MCM5, MCM6, MCM7, PCNA, RRM2 }\end{array}$ \\
\hline MYC & & Inhibited & -4.281 & $6,01 \mathrm{E}-08$ & $\begin{array}{l}\text { AIMP2, BRCA1, BUB1B, C12orf49, CCNA2, CDC20, } \\
\text { CDC25A, CDK1, CDK6, CHEK1, DNMT1, E2F1, } \\
\text { EZH2, KRAS, MAX, MCM5, MCM6, MCM7, PCNA, } \\
\text { POLD1, RCC1, RRM2, SHMT1, SHMT2, SLC7A5, } \\
\text { STMN1, TYMS, UBE2C }\end{array}$ \\
\hline TP63 & & Inhibited & -2.236 & $1,58 \mathrm{E}-07$ & $\begin{array}{c}\text { ABI2, BRCA1, CCNA2, CDK1, CDK6, DNMT1, } \\
\text { FANCA, MAPK8, PCNA, PRNP, RAC2, RACGAP1, } \\
\text { RCC1, SEPHS1 }\end{array}$ \\
\hline
\end{tabular}

